\title{
Earthquake Hazard in the Heart of the Homeland
}

$\mathrm{E}$ vidence that earthquakes threaten the Mississippi, Ohio, and Wabash River valleys of the Central United States abounds. In fact, several of the largest historical earthquakes to strike the continental United States occurred in the winter of 1811-1812 along the New Madrid seismic zone, which stretches from just west of Memphis, Tenn., into southern Illinois (fig. 1). Several times in the past century, moderate earthquakes have been widely felt in the Wabash Valley seismic zone along the southern border of Illinois and Indiana (fig. 1). Throughout the region, between 150 and 200 earthquakes are recorded annually by a network of monitoring instruments, although most are too small to be felt by people. Geologic evidence for prehistoric earthquakes throughout the region has been mounting since the late 1970s. But how significant is the threat? How likely are large earthquakes and, more importantly, what is the chance that the shaking they cause will be damaging?

Like many natural phenomena, how and why earthquakes happen, and their effects, depend on many factors. Studying earthquakes is especially challenging because they happen infrequently and without any advanced warning. Also, the processes that cause earthquakes work deep beneath the Earth's surface and over many thousands of years. Nonetheless, research during the last 20 years has led to new understanding, particularly with respect to earthquakes in the New Madrid seismic zone. Not surprisingly, as the understanding of earthquakes evolves, so do the estimates of the hazard that they pose.

\section{Estimating Earthquake Hazards}

Earthquake hazard refers to the consequences of an earthquake that may disrupt the normal activities of people or cause them loss. Most damage is due to ground shaking caused by waves that emanate from the abrupt fault movement during an earthquake. Seismic hazard maps depict the ground shaking that is expected to be exceeded at a selected probability (or chance) over a specific time period. Estimates of this "probabilistic" ground shaking, or hazard, at any given location must account for many factors including the possible shaking from all likely earthquakes and the types of rocks and soil in the region.
The USGS produces earthquake (seismic) hazard maps on a national scale (fig. 2). Hazard maps are also now produced in select urban areas. At either scale there are a suite of maps for different probabilities and time periods; the choice of which to use depends upon the needs of the user. Builders of a dam, for instance, might want to consider longer periods of time and less likely levels of shaking than a home builder. This is because a dam is built to have a longer life, and damage to it would have a greater impact on society.

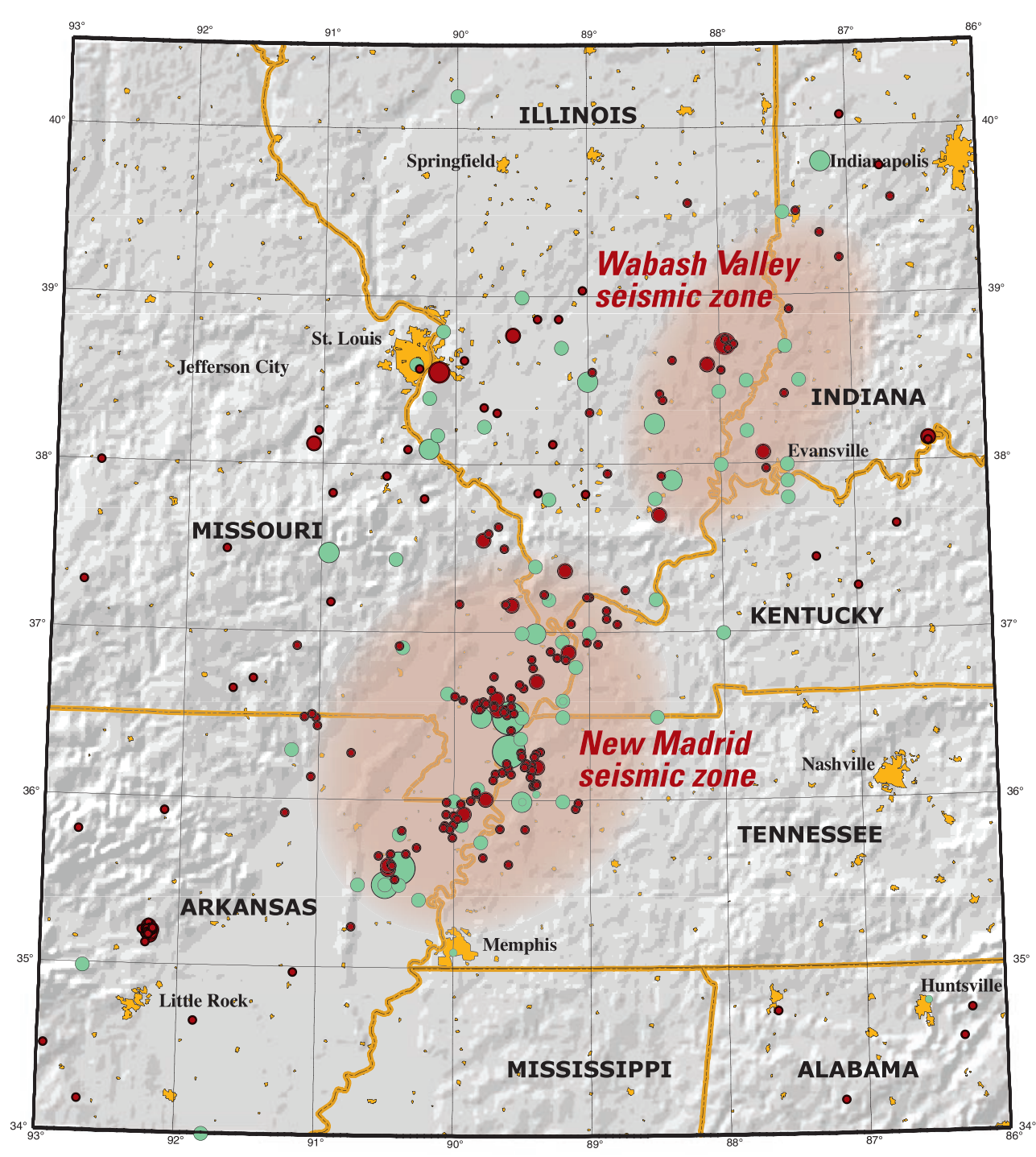

Figure 1. This map of the New Madrid and Wabash Valley seismic zones shows earthquakes as circles. Red circles indicate earthquakes that occurred from 1974 to 2002 with magnitudes larger than 2.5 located using modern instruments (University of Memphis). Green circles denote earthquakes that occurred prior to 1974 (USGS Professional Paper 1527). Larger earthquakes are represented by larger circles. 


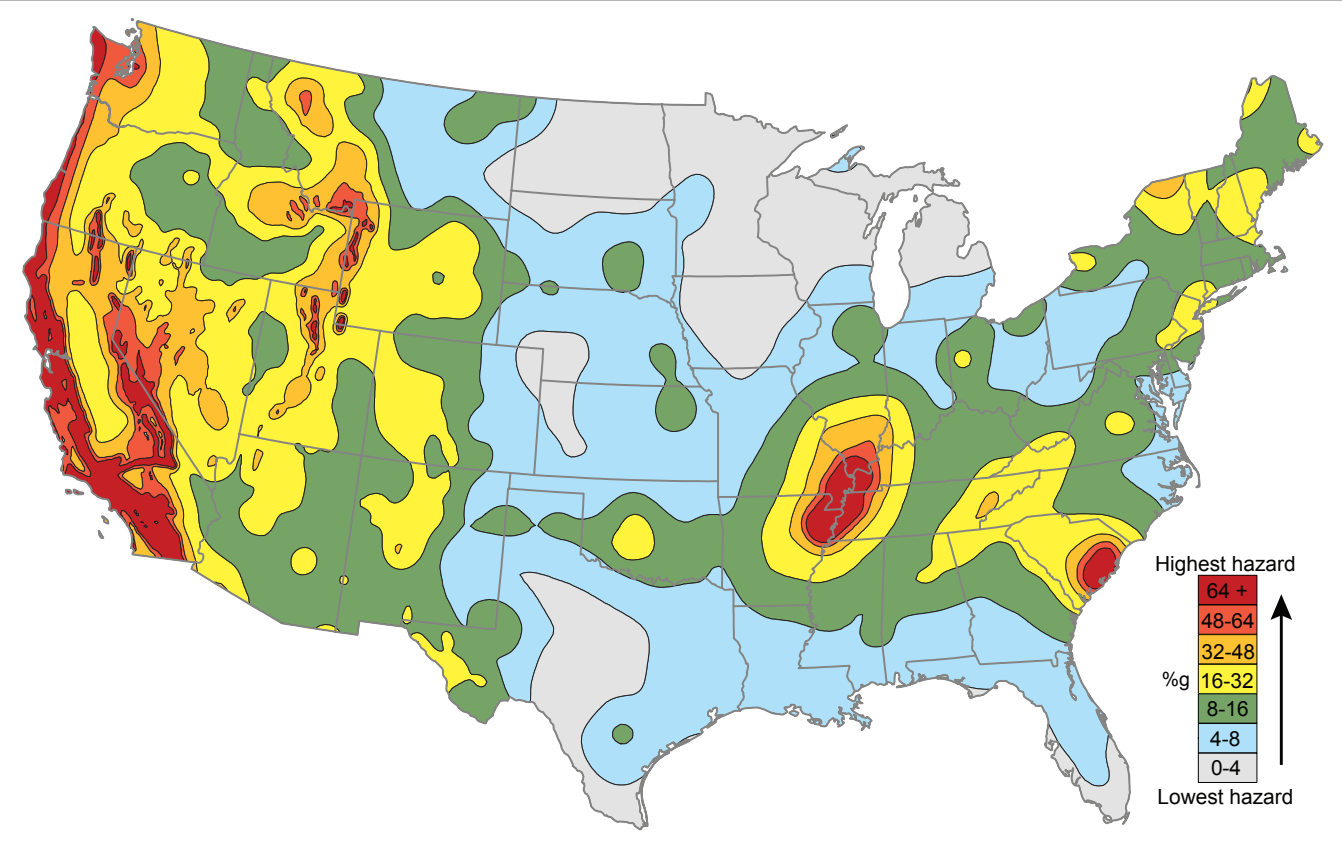

Figure 2. The U.S. Geological Survey shaking-hazard maps for the United States are based on current information about the rate at which earthquakes occur in different areas and on how far strong shaking extends from earthquake sources. Colors on this particular map show the levels of horizontal shaking that have a 1 -in- 50 chance of being exceeded in a 50 -year period. Shaking is expressed as a percentage of $\mathrm{g}(\mathrm{g}$ is the acceleration of a falling object due to gravity).

\section{Earthquake Hazards in the Central United States}

One of the most prominent features on the national seismic hazard maps is a zone of high hazard surrounding the New Madrid region in the Central United States. By some measures, the hazard in this region is as high as for places in California. Buried sand-blow deposits within the Mississippi River valley are believed to be the by-product of strong ground shaking associated with large past earthquakes (see "Digging Up the Past"). These deposits and the major earthquakes that caused them have been dated at about A.D. 900 and A.D. 1450.

A five-hundred-year interval between magnitude 7 or greater earthquakes in the Mississippi River valley is much more frequent than expected. Elsewhere scientists use the frequency of small and moderate earthquakes to estimate the likelihood of larger events, but in the New Madrid region, this rule of thumb does not appear to apply. In other words, in the New Madrid region, the rate of occurrence of major earthquakes and the high hazard they pose is comparable to that in California, whereas smaller earthquakes occur much less often. These smaller events remind us about the less frequent, but more hazardous major earthquakes. In the New Madrid region, we lack these reminders, but not the hazard associated with the major earthquakes. Additionally, large earthquakes in the New Madrid region seem to happen much more frequently than predicted from extremely accurate satellite-based measurements of ground deformation. These measurements show that the Earth's crust is being deformed, or strained, extremely slowly, if at all. This is in contrast to California, where the rate of major earthquakes is predictable based on measured deformation.

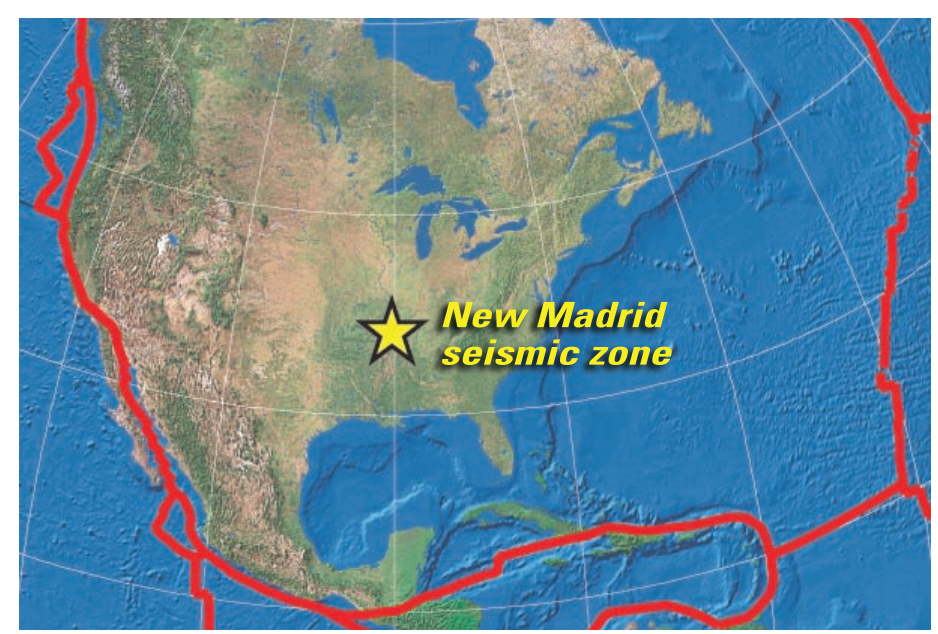

Figure 3. On this shaded topographic relief map, the New Madrid seismic zone is shown by a star, and the boundaries of the North American and surrounding plates are indicated by red lines. Mountainous regions tend to occur near plate boundaries, resulting from the motions between plates. The nearest plate boundary to the New Madrid seismic zone is many thousands of kilometers away. 


\title{
Far from a Plate Boundary
}

Why does the Central United States have more large earthquakes than expected? Why is it so different from California? The answers to these questions are still unknown, but scientists now ask whether there might be fundamental differences between the geologic processes at, and away from, plate boundaries (fig. 3). The New Madrid region is far away from any tectonic plate boundary, and thus applying what has been learned from studies of places like the San Andreas fault in California to the New Madrid region may not be appropriate.

\section{Factors Controlling Ground Shaking}

In addition to earthquake recurrence, hazard also depends on how amplitudes of earthquake waves die out as they move away from the earthquake source to the affected site. It is well known that wave energy decreases much more slowly in the Central and Eastern United States than in the West. For the same size earthquake, this leads to greater shaking over larger areas, or higher hazard, in the Central and Eastern United States.

Earthquake shaking also may be significantly amplified or damped by the soils immediately beneath a site (fig. 4). This is particularly true for the thick sediments that underlie most of the New Madrid seismic zone. Recent research has highlighted the potential amplification of ground shaking by these thick sediments and has begun to shed light on the physical processes that cause this. Because characterization of this amplification requires detailed mapping of the soils and their properties, amplification characteristics are not included in the National Seismic Hazard Maps. Efforts are underway, however, to produce maps that do show these amplification characteristics on scales appropriate for use in urban planning, earthquake hazard mitigation, and response planning efforts.

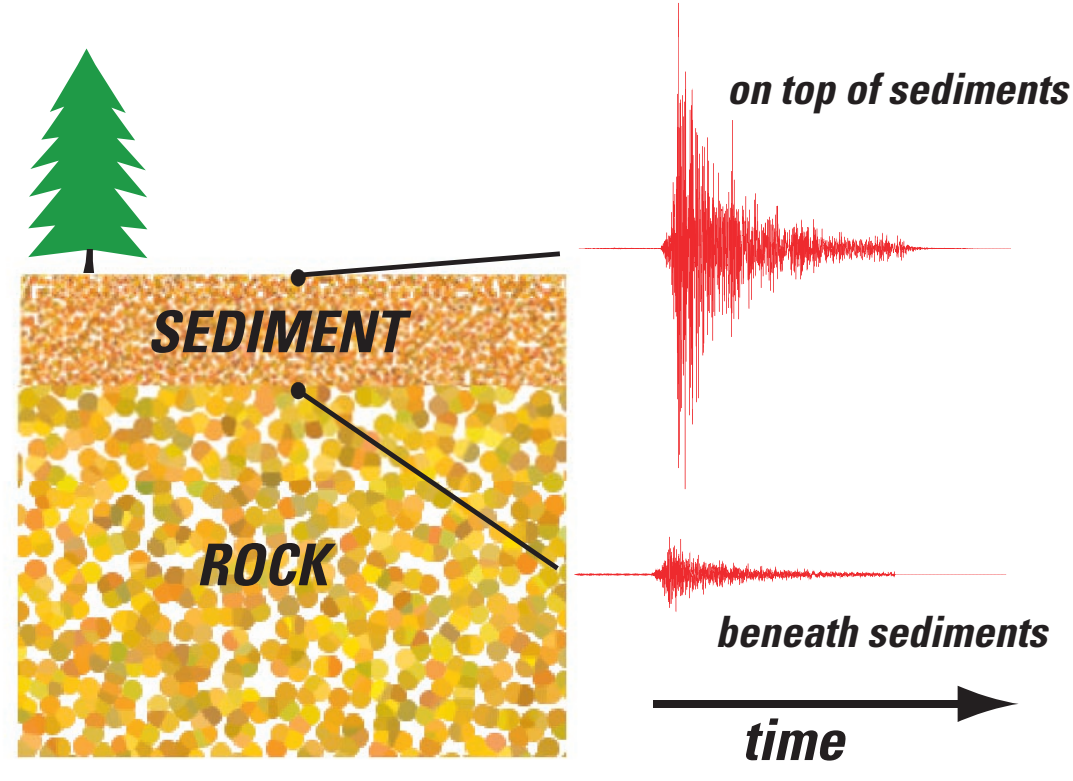

Figure 4. When waves of a small earthquake impinge on the boundary between hard rock and overlying sediments from below (lower seismogram), they become amplified as they travel through the sediments to the surface (upper seismogram). A seismogram records the wave motion over time. The amplifying effects of thick sediments above the New Madrid seismic zone results in motions at the surface that are many times larger than below. (Courtesy of C. Langston, The University of Memphis.)

\section{How Likely is a New Madrid Earthquake?}

In much the same way as meteorologists forecast rain, earth scientists present forecasts of earthquakes as the chance or "probability" of an earthquake occurring in a specific time interval. Although we are still learning why the New Madrid region experiences large earthquakes, research during the last 15 years in the Central United States has led to new discoveries that, not surprisingly, have led to new estimates of the likelihood of damaging earthquakes. It is generally accepted that earthquakes can be expected in the future as frequently as in the recent past. We determine how often earthquakes recur from historical and geological studies (see "Digging Up the Past"). Using these data, which were also used to produce the National Seismic Hazard Maps, the USGS and the Center for Earthquake Research and Information of the University of Memphis now estimate that for a 50-year time period:

\author{
Probability of a repeat of the 1811-1812 earthquakes \\ (magnitude 7.5-8.0) $=7-10 \%$
}

Probability of a magnitude 6.0 or larger $=25-40 \%$ 
Earthquakes in the approximate range of magnitude 7.5 to 8.0 are capable of causing widespread damage over a large region. Magnitude 6.0 earthquakes can cause serious damage in areas close to the earthquake's location. It is important to remember that earthquake damage mostly results from the shaking associated with the waves emitted by the earthquake. The probability of damaging shaking, or hazard, depends on much more than earthquake size. These other factors, such as how far away the earthquakes occur and local soil conditions, must also be considered when assessing the hazard posed by earthquakes.

\section{Digging Up the Past}

To determine the earthquake hazard of an area, scientists need to know how often the largest earthquakes occur. This is difficult because the time between major earthquakes is much longer than the time period for which we have modern instrumental measurements or even historical accounts of earthquakes. Fortunately, scientists have found a sufficiently long

\section{Buried prehistoric sand blow}

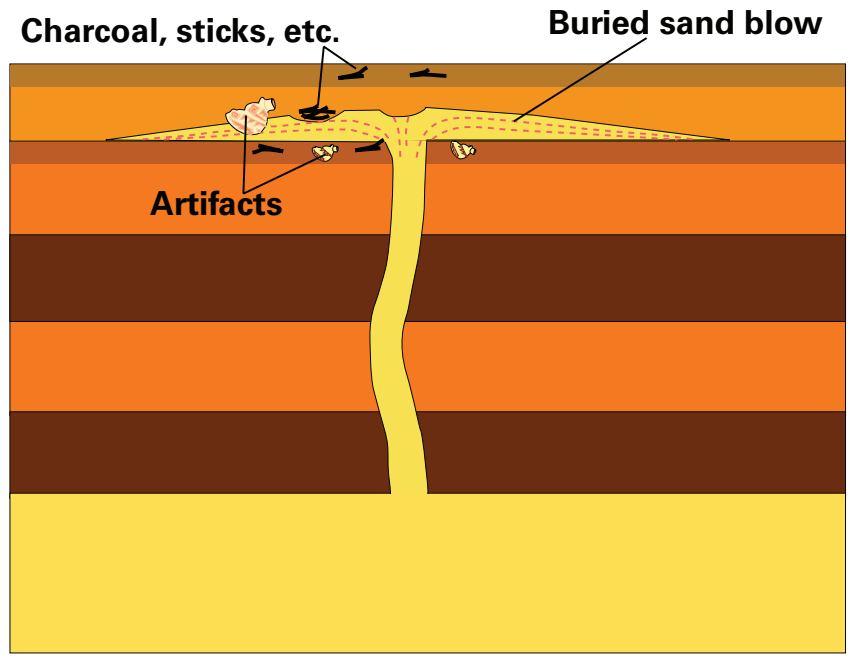

record of past earthquakes that is preserved in the rock and soil beneath our feet. The unraveling of this record is the realm of a field called "paleoseismology." In the Central United States, abundant sand blows are studied by paleoseismologists. These patches of sand erupt onto the ground when waves from a large earthquake pass through wet, loose sand. The water pressure increases, forcing the sand grains apart until the sand starts to behave like a liquid ("liquefies"), and a slurry of sand and water is forced to the ground surface. If the age of material buried by the erupted sand can be determined (for example, by using Native American artifacts or plant remains), then we know the earthquake must have occurred after this date. If the sand blow is itself buried by something that can be dated, then we know the earthquake happened before this date. We now know that a series of large earthquakes, similar in size and location to those in 1811-1812, have occurred twice in the past 1,200 years, once between A.D. 800 and 1000, and again between A.D. 1300 and 1600 , or about once every 500 years.

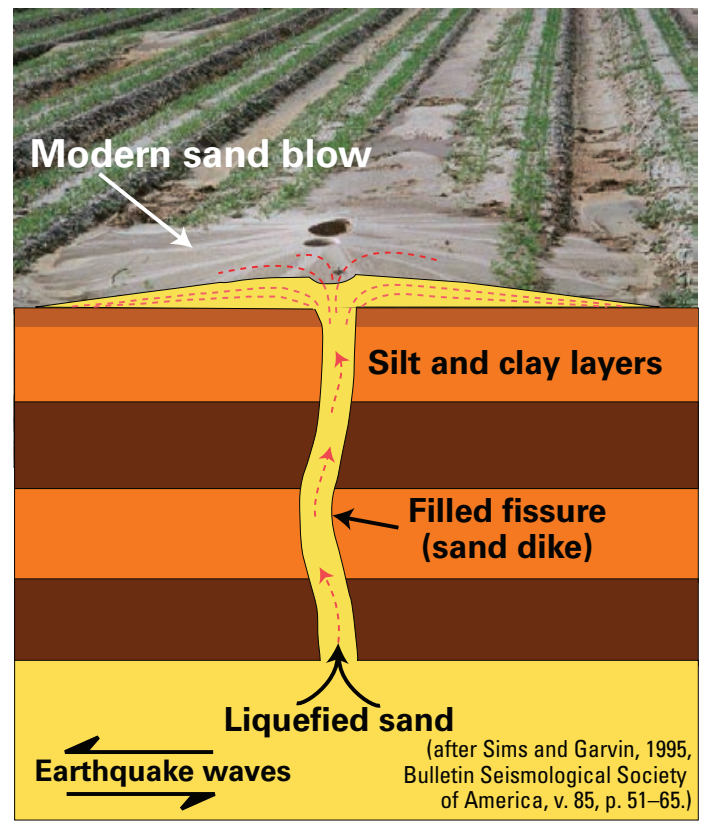

\section{For more information, contact:}

Eugene Schweig

U.S. Geological Survey

3876 Central Avenue

Suite 2

Memphis, TN 38152-3050

901-678-4974

schweig@usgs.gov
Written by Joan Gomberg and Eugene Schweig

Publication layout by Sharon Powers

This fact sheet is available online at http://pubs.usgs.gov/fs/2006/3125 